\title{
A TRAJETÓRIA HISTÓRICA DA IDEOLOGIA NEOLIBERAL E SUAS IMPLICAÇÕES NAS POLÍTICAS PÚBLICAS EDUCACIONAIS DO BRASIL
}

\author{
Virna Lumara Souza LIMA ${ }^{1}$ \\ Universidade Federal do Acre - UFAC \\ virnalumara@gmail.com
}

Resumo: Diante do surgimento de uma nova forma de gerenciar a administração pública brasileira, advinda dos preceitos que regem a iniciativa privada, em cujo discurso repousa a ideia da busca por qualidade nos serviços $e$ eficiência no uso dos recursos financeiros, é possível perceber que o Estado tem sofrido uma reconfiguração, trazendo consequências às chamadas políticas sociais. É possível, portanto, vislumbrar um rito de passagem do chamado Estado de Bem-estar social para o Estado neoliberal. Nas políticas educacionais, em especial, o Estado Mínimo, proposto pelo neoliberalismo, e a perspectiva gerencial na administração pública trouxeram diversas implicações que podem ser mais bem compreendidas ao avaliar como tais proposições adentraram no contexto brasileiro. Este artigo tem o objetivo de refazer a trajetória pela qual tais preceitos foram introduzidos no Brasil, culminando na mudança de comportamento do Estado para com as políticas públicas educacionais, além de trazer à reflexão as principais implicações na educação brasileira.

Palavras-Chave: Estado; Neoliberalismo; Políticas públicas educacionais.

\begin{abstract}
Faced with the emergence of a new way of managing a Brazilian public administration, derived from the precepts that govern a private initiative, issue speech rests an idea of the search for quality our services and efficiency no use of financial resources, it is possible to perceive that the State Suffered a Reconfiguration, bringing consequences in the so-called social policies. It is therefore possible from a Member State of Social Welfare to the neoliberal State. In educational policies, in particular, the Minimum State, proposed by neoliberalism, and the managerial perspective in public administration have brought different implications that can be better constructed when assessing how these propositions entered the Brazilian context. This article aims to develop a platform through prerequisites and presentations in Brazil, culminating in the change of the State's behavior towards public educational policies, in addition to bringing to reflection as the main implications in Brazilian education.
\end{abstract}

Key-Words: State; Neoliberalism; Educational public policies.

\footnotetext{
${ }^{1}$ Mestrado em andamento em Educação pela Universidade Federal do Acre - UFAC. Licenciada em Letras - Língua Portuguesa EM 2013. Foi voluntária do Programa Institucional de Voluntários de Iniciação Científica (PIVIC) e bolsista do Programa de Educação Tutorial (PET), atuando em atividades de pesquisa, ensino e extensão na área de Letras. Exerceu o magistério na educação básica no Sistema Público de Ensino do Acre, por meio da Secretaria Municipal de Educação (SEME) de Rio Branco e da Secretaria de Estado de Educação e Esporte (SEE) do Acre, atuando no Programa Projovem Urbano e em Escola de Ensino Fundamental, respectivamente. Atualmente, faz parte do quadro de servidores técnico-administrativos da Universidade Federal do Acre - UFAC
} 


\section{Introdução}

As políticas públicas, em especial as que se situam no campo educacional, são mais bem compreendidas quando as analisamos a partir de seu contexto de produção. Isso porque as questões sociais, políticas e econômicas de um país possuem influência direta na forma como o Estado delimita suas necessidades e executa os serviços públicos dirigidos à sociedade como um todo. Subjacente a isso, como pode ser observado no decorrer da história, o Estado possui uma tendência ideológica que condiciona as suas ações. E é justamente devido a essa ideologia, pela qual se submete o Estado, que Laswell (1936 apud SOUZA, 2006, p. 20) afirma que "as decisões e análises sobre essa temática implicam respostas sobre quem ganha o quê, por quê e que diferença faz.”.

Dessa forma, é impossível discutir as políticas públicas de uma sociedade sem que se estabeleça uma relação de reciprocidade entre elas e o Estado. E isso se deve à ideia de que as políticas públicas refletem de forma efetiva não somente a ação do Estado, mas também a carga ideológica em que fundamenta tal ação. É por meio das políticas públicas que o Estado implanta os seus projetos de governo e os efetiva através de diversas ações voltadas para áreas específicas da sociedade. Diante de tais afirmações, é interessante considerar a diferenciação que há entre Estado e Governo. Segundo Höfling,

É possível se considerar Estado como o conjunto de instituições permanentes como órgãos legislativos, tribunais, exército e outras que não formam um bloco monolítico necessariamente - que possibilitam a ação do governo; e Governo, como o conjunto de programas e projetos que parte da sociedade (políticos, técnicos, organismos da sociedade civil e outros) propõe para a sociedade como um todo, configurando-se a orientação política de um determinado governo que assume e desempenha as funções de Estado por um determinado período. (HÖFLING, 2001, p. 31).

Dessa forma, a autora alerta que, tendo em vista a necessidade de órgãos públicos e diferentes organismos e agentes da sociedade agirem na tomada de decisões que envolvem a implementação e manutenção das políticas, estas são de responsabilidade do Estado. Importante destacar que são diversos os conceitos que tentam definir o conceito de políticas públicas. Mas vale a pena destacar que a temática se situa em um campo amplo, pois, segundo Dye (1984 apud SOUZA, 2006), "refere-se a tudo o que o governo escolhe fazer ou não fazer". Outras definições 
citam ainda a relação do papel das políticas públicas com a solução de problemas em uma dada sociedade.

No que se refere à formulação das políticas, Souza (2006, p. 27) tem algumas ideias discordantes, nas quais se destaca "que o Estado reflete apenas as pressões dos grupos de interesse ou opta por políticas definidas exclusivamente por aqueles que estão no poder ou, ainda, que atende apenas aos interesses de determinadas classes sociais". A autora reconhece a ação de outros segmentos, além do governo, tais como grupos de interesse e movimentos sociais, na formulação de políticas, mas enfatiza uma autonomia relativa por parte do Estado, conferindo a ele um espaço próprio de atuação, criando condição para a implementação de objetivos de políticas públicas.

Ainda no que se refere ao conceito e à formulação de políticas, a autora enfatiza que:

Pode-se, então, resumir política pública como o campo do conhecimento que busca, ao mesmo tempo, "colocar o governo em ação" e/ou analisar essa ação (variável independente) e, quando necessário, propor mudanças no rumo ou curso dessas ações (variável dependente). A formulação de políticas públicas constituise no estágio em que os governos democráticos traduzem seus propósitos e plataformas eleitorais em programas e ações que produzirão resultados ou mudanças no mundo real. (SOUZA, 2006, p. 26).

Vale a pena destacar, ainda, que, no processo de formulação de políticas, o papel do

Estado é preponderante, mas não se finda nele. Como atores que emergem nesse meio, surgem ainda as classes sociais e sociedade civil.

Em um plano mais específico, em termos conceituais, situam-se as políticas sociais. De acordo com Höfling (2001), “elas estão relacionadas às ações que visam um padrão de proteção social desenvolvido pelo Estado, a partir de redistribuição de benefícios sociais, com o intuito de diminuir as desigualdades resultantes do desenvolvimento socioeconômico". É a partir das políticas sociais, portanto, que se efetiva a garantia de direitos que asseguram condições sociais e econômicas dignas e, em princípios, justas, para que a população exerça, de fato, a cidadania. Dentre as áreas de atuação, é possível citar, principalmente, saúde, trabalho, assistência e previdência social, justiça e a educação, sendo esta última o foco de análise deste ensaio. 
Trajetória histórica e primeiras características dos estados liberal, de bem-estar social e neoliberal

A ideologia liberal da ação do Estado remonta, portanto, aos séculos XVII e XVIII, com o advento do Iluminismo na Europa. Um movimento que provocou grandes mudanças no meio econômico, político e social à época, apregoando o uso da razão e de maior liberdade econômica e política, sob o mantra dos ideais de liberdade, igualdade e fraternidade. Buscava, portanto, a limitação do poder do Estado sobre a vida e as escolhas dos cidadãos, com grande ênfase nas questões econômicas, percebidas efetivamente nas críticas dirigidas ao mercantilismo².

O Estado Liberal, que possuía como principais representantes o Reino Unido e os Estados Unidos, permaneceu como modelo hegemônico até o início do século XX. Entretanto, importantes acontecimentos históricos, como as duas guerras mundiais e a crise econômica de 1929 (Grande Depressão) provocaram uma profunda crise nesse modelo, culminando em uma abertura para a consolidação de uma nova proposta de Estado que ficou conhecida como Welfare State, ou Estado de Bem-estar Social. Dentre as definições existentes, destacamos a de Medeiros (2001, p. 6) que afirma que, "a Welfare State é entendida como a mobilização em larga escala do aparelho de Estado em uma sociedade capitalista, a fim de executar medidas orientadas diretamente ao bem-estar de sua população.”.

A solução para a crise em que se encontrava a economia foi justamente a retomada de ações efetivas pelo Estado, a partir da década de 1930. Além da questão econômica, a ideia desse modelo também surge em oposição aos regimes nazista e fascista, caídos após a Segunda Guerra Mundial. A efeito da disputa entre Estados Unidos e União Soviética, durante a Guerra Fria, o Estado de Bem-estar Social surge também como uma alternativa às ideias socialistas com o objetivo de conter seu estímulo e disseminação entre os trabalhadores.

Importante ressaltar, a partir disso, que as ideias que sustentam essa nova perspectiva de Estado são advindas de pensamentos liberais, e que, portanto, não havia uma intenção de modificar substancialmente o papel do Estado, mas adequá-lo de acordo com as necessidades que se faziam presentes, diante do cenário social e, principalmente, econômico. A exemplo disso, é possível citar

\footnotetext{
${ }^{2}$ O Mercantilismo consistiu na prática econômica adotada na Idade Moderna, marcada, principalmente, pela forte intervenção do Estado. 
a obra do economista John Maynard Keynes (1883 - 1946), cujos pensamentos fundamentaram essa nova interpretação de Estado, em que o ideário se pauta na necessidade de distribuir melhor a renda de produção, dando prioridade ao consumidor, tendo em vista que esse é quem determinaria o volume de produção. Ele chamava, portanto, a atenção para a garantia do pleno emprego, para que houvesse um equilíbrio entre demanda e produção, evitando a redução de lucro dos capitalistas.

Os primeiros países a se utilizarem da doutrina de Keynes (Keynesianismo) para a construção de suas políticas econômicas foram os Estados Unidos e, posteriormente, o Brasil, com uma abordagem diferenciada, durante a Era Vargas. Só após o sucesso do Estado Keynesiano nos EUA, após a Segunda Guerra Mundial, as ideias foram difundidas nas políticas da Europa Ocidental, fundamentando o Estado de Bem-estar Social. Nesse momento, tem-se, portanto, uma nova perspectiva de Estado, predominante nos países ocidentais, a partir da metade do século XX, que surge em defesa do crescimento do mercado, mas com a regulamentação estatal, para que fossem garantidos o crescimento efetivo na economia e a oferta de benefícios sociais, garantidos por meio de bens e serviços públicos.

Em termos históricos, o avanço das ideias neoliberalistas deu-se por volta de 1970, tendo como principal atuante do movimento o economista Milton Friedman. Uma nova interpretação sobre a postura do Estado, diante da economia, desenvolveu-se, supostamente, como forma de solucionar as crises que atingiram a economia mundial, com destaque para a Crise do Petróleo, em 1973, devido ao aumento excessivo de seu preço. O Neoliberalismo, vale destacar, nada mais é que uma retomada dos ideais que fundamentaram o Estado Liberal do século XVIII, mas com algumas diferenças, principalmente quanto ao papel do Estado.

A partir desse momento histórico, é interessante ressaltar que o papel do Estado frente às questões econômicas é novamente questionado, tendo em vista as circunstâncias em que o mundo capitalista se encontrava. Os defensores do ideário neoliberal responsabilizam o Estado pela crise no cenário econômico. Dessa forma,

As narrativas neoliberais oferecem explicações para a crise e alternativas para a sua superação. Suas causas estariam nos problemas derivados das políticas sociais, pois os custos crescentes, os efeitos destrutivos e os resultados desastrosos acentuavam a crise. Em contrapartida, a superação da crise estava na hegemonia do mercado como mecanismo de alocação de recursos, de distribuição de bens, serviços e rendas e como remunerador dos empenhos e engenhos. $\mathrm{O}$ mercado configura-se como base da riqueza, da eficiência e da justiça, sendo que a 
intervenção estatal sobre a economia deve ser controlada legalmente, pois acabam por desviar recursos das atividades produtivas para atividades improdutivas. (MORAES 2002 apud FARIAS, 2014, p. 270-271).

No que se refere às políticas educacionais, por exemplo, segundo a visão neoliberal, o Estado é incapaz de as gerir. Dessa forma, de acordo com Gentili (1998 apud FARIAS, 2014, p. 273), "seria necessário transferir a educação da esfera política para a esfera do mercado, negando sua condição de direito social e transformando-a em uma possibilidade de consumo individual, variável segundo o mérito e a capacidade dos consumidores”. O cenário econômico argumenta, portanto, que a lógica do mercado deveria ser predominante. Dessa forma, de acordo com Moraes,

O funcionamento da ordem de mercado é visto como um paradigma, um modelo de funcionamento para outras instituições sociais. Assim a pretensão destes analistas [neoliberais] é descobrir quais as regras constitucionais que, no plano das decisões coletivas (não-mercado), mais se aproximam da perfeição exibida por essa ordem (a do mercado). É o que chamam de economia constitucional, uma nova teoria do contrato social, que proporcione uma reconstrução da ordem social e política. (MORAES, 2001, p. 49).

Conveniente destacar, porém, que autores, como por exemplo Meszáros, defendem a perspectiva de uma crise estrutural do capital, contrapondo-se aos defensores do Neoliberalismo. O autor argumenta que os sinais dessa crise começaram a se evidenciar a partir da década de 1970, culminando na organização da ordem mundial, visível nos anos 1990, na qual se observava um processo de globalização econômica e financeira. A crise estrutural do capital foi, segundo essa perspectiva, precedida por uma longa fase de acumulação de capital, desde 1914. Após isso, houve uma demanda por políticas de liberalização, privatização, desregulamentação, e de diminuição de conquistas sociais e democráticas. Em resposta à própria crise, foi iniciado um processo que se pautou em uma nova organização do capital e de suas bases ideológicas, por meio da qual se vê, de fato, as ideias neoliberais sendo implantadas e proliferadas.

\section{Políticas públicas a partir do viés do estado de bem estar social e da lógica neoliberal - o contexto brasileiro}

\section{Estado de Bem Estar Social}


Partindo da perspectiva da crise no plano econômico, no Brasil, assim como nos principais países cujas ideias neoliberais floresceram, a crise foi encarada como advinda do Estado. A implantação do Estado de Bem-estar no Brasil antecede as circunstâncias pelas quais o Neoliberalismo adentrou ao país e auxilia na compreensão por meio do viés histórico. De início, vale a pena destacar que o processo de implantação do Estado de Bem-estar no Brasil se diferencia dos países europeus e norte-americanos, tendo em vista a sua posição diferenciada na economia mundial e, por questões particulares do país, de cunho histórico.

No Brasil, o Estado de Bem-estar surgiu por volta de 1930, segundo Medeiros (2001, p. 10), “a partir de decisões autárquicas e com caráter predominantemente político: Regular aspectos relativos à organização dos trabalhadores assalariados dos setores modernos da economia e da burocracia.". Ainda segundo o autor, a constituição desse modelo no Brasil teve um profundo caráter autoritário e conservador, no qual os antagonismos entre classes eram encarados como nocivos ao bem comum representado pelo Estado.

Quanto a essa postura, é importante destacar que - enquanto nos países norte-americanos e europeus o Keynesianismo surgiu pautado na perspectiva de que, ao distribuir melhor a renda da população, o consumidor seria protegido visto que ele é o responsável pelo lucro capitalista, garantindo assim o equilíbrio entre a demanda e a capacidade de produção - a abordagem brasileira do Welfare State baseou-se, principalmente, na regulação de aspectos relacionados à organização dos trabalhadores assalariados em setores modernos econômicos.

$\mathrm{O}$ autor afirma ainda que a utilização do Walfare State como instrumento de demanda agregada era minimizada devido ao fato de que problemas com superprodução estavam mais relacionados ao setor externo que à demanda nacional, além do fato de que a efetividade das políticas se estendia a poucos beneficiários, diminuindo, assim, a possibilidade de se utilizar de tais políticas como mecanismo de expansão de consumo.

Entre os anos de 1930 a 1943 - englobando a vigência do Estado Novo - a produção legislativa, de acordo com Draibe (1989), "esteve principalmente comprometida com a criação de institutos de aposentadoria e pensões e, também, com a legislação trabalhista, tendo em vista a criação da Consolidação das Leis do Trabalho (CLT)". Nesse período, também se vê o desenvolvimento de outras ações que resultaram na criação da Carteira de Trabalho, do salário mínimo, do descanso semanal remunerado e da Justiça do Trabalho. Além disso, segundo Draibe 
(1989, p. 8), é possível constatar diversas alterações nas políticas relacionadas à saúde e à educação, que evidenciaram a centralização de políticas, principalmente no que tange a recursos, instrumentos institucionais e administrativos, na figura do Executivo Federal.

Ao relacionar tais ações com a ideia que fundamenta o conceito do Estado de Bem-estar Social, é possível asseverar que há fortes indícios da implantação desse modelo de Estado nesse período, apesar do autoritarismo presente na administração da época. Tal autoritarismo fica visível na criação da Lei de Segurança Nacional, em 1935, que dificultou a capacidade de organização de classes, uma vez que a ascensão de movimentos políticos de oposição era reprimida.

Entre 1945 e 1964, o Brasil viveu a fase de democracia populista em sua política. Entretanto, no que se refere ao desenvolvimento do Estado de Bem-estar Social, não houve grandes mudanças, resultando em um cenário na qual diversas ações dos anos anteriores permaneceram intactas. Por outro lado, mudanças na economia e na política, nesse período, demandaram do Estado uma ampliação e maior articulação no suprimento das necessidades advindas do aprofundamento da concentração urbana e modernização do país. Com a chegada dos militares na administração do país, a partir de 1964, o modelo de política social delineada nesse período advinha da ideia de que o progresso social era decorrente do crescimento econômico, como escreve Martini (1989 apud MEDEIROS, 2001). Desse modo, para garantir o tal crescimento, enfatizaram a necessidade da concentração de renda no núcleo capitalista, cuja redistribuição seria feita posteriormente. Tendo em vista a diminuição de recursos para as políticas sociais, foram implementadas políticas de natureza assistencialista, como forma de compensação, além de garantir certa estabilidade política.

Entre os períodos de 1970 e fins da década de 1980, apesar das medidas de caráter universalista, o Welfare State brasileiro é definido, por meio da classificação de Draibe (1989), como meritocrático-particularista-clientelista. Tal classificação se deve à estratificação social decorrente de políticas específicas para grupos sociais diferentes, bem como à discriminação de determinadas ações para grupos específicos, que poderiam contribuir para a sustentação das políticas, além de medidas que favoreceriam grupos e cúpulas partidárias, visando benefícios em períodos eleitorais.

Com o advento da Nova República, declarando o término da Ditadura Militar, houve avanços na área política, que resultaram no crescimento da atividade partidária e sindical, além de 
uma participação mais efetiva da população no processo eleitoral. Observa-se, portanto, um processo de redemocratização na política brasileira. Em contrapartida, houve retração e até desmantelamento das políticas sociais, na qual não houve criação de programas com grande impacto, visto que alguns foram até desativados. As mudanças ocorridas entre 1985 e 1988 estão fundamentadas, principalmente, na crítica à centralização institucional e financeira no sistema (FAGNANI, 1997 apud MEDEIROS, 2001, p. 17). Nesse período, destaca-se, principalmente, a promulgação da nova Constituição Federal, em outubro de 1988, que, de acordo com Draibe (1989, p. 218), "introduziu avanços formais, corrigindo iniquidades e ampliando direitos, especialmente no campo trabalhista e na seguridade social.”.

Depreende-se, portanto, que a Constituição Federal de 1988 foi um grande marco não apenas nesse momento, mas em toda a periodização que delimita o Estado de Bem-estar no Brasil. A sua promulgação rompeu, ainda que ideologicamente, com o perfil meritocrático e particularista que predominava na administração pública brasileira, pois passou a ampliar direitos sociais e expandir o acesso às políticas sociais. Com isso, aumentaram-se também as responsabilidades do Estado para com a população - ação que se relaciona com as principais ideias que fundamentam esse modelo de administração.

\section{Inserção dos Ideais Neoliberais no Brasil}

A partir dos anos 1990, a exemplo do que já estava acontecendo em países que haviam vivenciado o Welfare State no contexto global do capitalismo, o Brasil também se encaminhou para um perfil mais liberal da economia e, consequentemente, das políticas públicas sociais, incluindo as educacionais. Nesse momento, vale recordar que a crise estrutural do capital ficou claramente perceptível na década de 90, antecedido por um intenso processo de globalização econômica e financeira.

Vale destacar ainda que, além do Brasil, outros países da América Latina vivenciaram a inserção de ações de cunho neoliberal em suas políticas públicas. E isso se deu a partir da renegociação das dívidas externas que os levou a colocar em prática um ajuste fiscal, visando, principalmente, o pagamento das dívidas aos países credores. Registre-se ainda o papel de instituições financeiras tais como o Fundo Monetário Internacional (FMI) e o Banco Mundial no processo de concessão de empréstimos e na negociação de prazos para o pagamento das dívidas. 
O contato inicial do Brasil com as políticas neoliberais deu-se no governo de Fernando Collor de Mello, no início da década de 90, momento em que era possível vislumbrar concepções neoliberais nas políticas econômicas que se apoiavam, principalmente, na mudança do papel do Estado, trazendo, segundo essa perspectiva, eficiência e competitividade. Durante seu curto tempo de governo, houve extinção de entidades governamentais, privatização de estatais e demissão e remanejamento de funcionários públicos, sem um planejamento específico. A máquina pública era vista como ineficiente e, portanto, incapaz de atender às demandas sociais. Entretanto, foi no governo de Fernando Henrique Cardoso que a reforma do Estado no Brasil foi concretizada por meio do Plano Diretor da Reforma do Aparelho do Estado (PDRAE), de 1995, elaborado pelo Ministério da Administração e Reforma do Estado (MARE), criado especialmente para tal atividade.

O Plano apresenta a reforma do Estado não somente como uma exigência advinda da globalização econômica, com o objetivo de inserir o Brasil na nova ordem mundial, mas também como uma necessidade, para que o país pudesse superar a crise do próprio Estado (PERONI; OLIVEIRA; FERNANDES, 2009). As estratégias de Reforma, de acordo com o PDRAE, baseavam-se na modernização da máquina pública, diminuindo o papel do Estado ao propor ações como o aumento da participação de entidades privadas na administração pública, a substituição da administração pública burocrática pela gerencial, o prosseguimento ao processo de privatização de empresas estatais, dentre outras ações, visando também à racionalização de recursos (BRASIL, MARE, 1995, p. 45). Ao ter como foco a reestruturação do Estado, o PDRAE proporcionou, portanto, o primeiro contato do Brasil com a Administração Pública Gerencial, que possui, dentre os seus fundamentos, o controle de resultados e o incentivo à competição.

As políticas sociais são claramente afetadas a partir dessa nova perspectiva de Estado, sob forte influência neoliberal. É justamente a partir dessa influência, visando à diminuição de gastos públicos, que a universalidade das políticas públicas tende a diminuir a sua capacidade, fazendo com que tais políticas alcancem apenas grupos classificados como emergenciais. Além disso, observa-se a ideia de descentralização e privatização, na qual as políticas seriam oferecidas por entidades privadas, que, segundo essa perspectiva, seriam mais competentes em sua execução. Dessa forma, o Estado vai se desobrigando cada vez no que se refere à promoção de serviços públicos, administrando-os apenas como um regulador. 


\section{O neoliberalismo e suas implicações para as políticas públicas educacionais}

É relevante a discussão desenvolvida acerca das ideias que fundamentam o Estado Neoliberal e como estas vêm sendo inseridas nas políticas públicas educacionais brasileiras. É importante ressaltar que a passagem do Estado de Bem-estar social para o Estado Neoliberal não acontece de uma forma pontual, mas de uma maneira gradual. No caso do Brasil, por exemplo, não é possível classificá-lo entre um modelo ou outro de forma tão enfática e decisiva, uma vez que há resquícios de ambos os modelos em suas políticas, embora haja, atualmente, uma tendência voltada a uma perspectiva mais neoliberal. A discussão sobre essa tendência do Estado a uma postura mais neoliberal na construção de suas políticas públicas e a forma com que essa ideologia foi se adentrando no contexto brasileiro são de suma importância para a discussão sobre as políticas sociais, em especial àquelas que envolvem a educação pública.

É importante ter em mente que a discussão que se faz problematiza, principalmente, quanto ao tamanho do Estado, principalmente no que se refere ao alcance de sua atuação junto às políticas sociais. Enquanto o Estado de Bem-estar social preconiza um Estado com uma grande atuação, o Neoliberal visa um Estado com ações apenas em questões bem pontuais e, mesmo assim, de forma mínima. Ao entrar especificamente na discussão sobre as ideias neoliberais no âmbito educacional, é importante destacar a influência de instituições econômicas internacionais, como o Banco Mundial, na construção das políticas nacionais. O papel de tal banco, de acordo com Soares,

Deve-se não apenas ao volume de seus empréstimos e à abrangência de suas áreas de atuação, mas também ao caráter estratégico que vem desempenhando no processo de reestruturação neoliberal junto dos países em desenvolvimento, por meio de políticas de ajuste estrutural. (SOARES, 1998, p. 15).

A influência de organismos internacionais, como o Banco Mundial, se dá justamente por meio de empréstimos concedido aos países subdesenvolvidos (ou em desenvolvimento) para financiar as políticas realizadas por esses países. Em contrapartida, são feitas exigências e estratégias que devem ser atendidas. No campo educacional, o Banco Mundial parte da premissa de que a educação é um instrumento de grande importância na promoção do crescimento econômico e na redução da pobreza. Entretanto, ao analisar o discurso sobre o combate à pobreza, 
o que se observa são indicações para programas meramente assistencialistas, que, na prática, não seriam capazes de oferecer possibilidades para a emancipação. As medidas, portanto, não possuem um grande peso de transformação social. Objetivam tão somente a reestruturação da situação econômica dos países, o que, a propósito, coincide com a perspectiva neoliberal.

Dentre as principais orientações propostas pelo Banco Mundial para as reformas educacionais, destacam-se, segundo Torres (1998), a prioridade para a educação básica, melhoria da qualidade e eficiência da educação, a prioridade sobre os aspectos financeiros e administrativos da reforma educativa e descentralizada, instituições escolares autônomas e responsáveis por seus resultados, uma maior participação de pais e comunidades nos assuntos escolares, setor privado e organismos não governamentais como agentes ativos nas decisões e a definição de políticas e prioridades baseadas na análise econômica. A partir dessas orientações, é visível a relação que há com o que postula o Neoliberalismo, uma vez que submete a educação à lógica mercadológica, ao minimizar o papel do Estado, colocando-o, geralmente, como financiador, mas atribuindo ao âmbito privado a responsabilidade administrativa. Partindo dessa perspectiva, a educação deixaria de pertencer ao campo social e passaria a ser um serviço disponibilizado por uma instituição privada, que visa atender a uma demanda de mercado.

No caso brasileiro, em específico, a política educacional foi inserida no projeto de reforma do Estado. Dessa forma, a educação foi fortemente influenciada pelas ideias neoliberais através da nova administração gerencialista, que passou a vigorar nas ações da administração pública a partir do PDRAE. Dentre as principais características da administração que passaram a ditar as reformas educacionais, a descentralização foi, de longe, a que mais representou mudanças significativas nas políticas educacionais. Por meio da descentralização, a Estado diminui a capacidade de sua intervenção, transferido o que era sua responsabilidade para a sociedade civil.

Foi por meio da descentralização que a União delegou funções aos Estados, e estes delegaram aos municípios, que, por sua vez, lançam mecanismos de responsabilização a organismos não-governamentais e à comunidade. Obviamente, essa é uma forma simples de exemplificar a descentralização na esfera administrativa. No campo educacional, a proposta representou, por exemplo, a transferência administrativa para a própria escola. Dessa forma, os problemas que sobreviveram ao contexto escolar passaram a ser encarados como problemas administrativos, decorrentes da ineficiência administrativa, devido à inserção de princípios da 
administração privada, deixando em segundo plano a problemática social e eximindo o Estado de responsabilidades.

A justificativa para a descentralização, não somente no âmbito educacional, mas também quanto aos demais serviços sociais, recai na ideia de otimização de recursos públicos aos prestálos à sociedade. Entretanto, o efeito que se tem notado desde então, principalmente a partir da descentralização, é justamente a responsabilização dos atores envolvidos a partir de resultados negativos, seja pelos recursos financeiros limitados, seja por demandas que advém de circunstâncias menos objetivas, relacionadas a uma perspectiva mais social.

Ainda decorrente dos princípios empresariais, adentram ao contexto das políticas educacionais os conceitos de avaliação e os mecanismo de controle, estabelecendo metas e padrões de rendimento, colocando o Estado na figura do regulador ou avaliador. Como resultado disso também é possível citar a precarização e desqualificação docente, uma vez que a concorrência, resultante de políticas de premiação, intensifica e aumenta a jornada de trabalho, para que, além de elevar o seu salário, os profissionais da educação não sofram sanções decorrentes do resultado fora do estabelecido. A partir disso, a escola, como um instrumento para a transformação social, perde completamente o sentido. Ela passa a estar em submissão à ordem capitalista, justificando, portanto, a presença de administradores do setor empresarial na formulação das políticas educacionais. Perde-se também o sentido de políticas públicas como instrumento minimizador das desigualdades sociais, uma vez que as medidas trazidas do universo mercadológico intensificam essa condição, justamente por deixar em segundo plano a perspectiva social.

\section{Considerações finais}

Toda ação executada por um Estado perante a sociedade é fundamentada a partir de uma ideologia. As políticas públicas, por serem o principal meio de efetiva ação do Estado, não são elaboradas apenas para lidar com uma situação pontual da sociedade. Para compreendê-las de uma maneira menos superficial, é, de fato, necessária uma análise mais específica, procurando responder a questões que fogem das políticas em si. Questionamentos sobre quem ganha o quê, por quê e que diferença faz, retomando o conceito apresentado inicialmente, faz mais sentido ainda quando situamos tais políticas em seus contextos de produção. 
Quando se analisam as políticas públicas, fixando como ponto de partida o advento do Estado Liberal, é perceptível o quanto a ideologia estabelece os limites e os rumos a serem traçados. Ao refazer, em linhas gerais, a trajetória do Estado Liberal até o Neoliberal, percebe-se que é no Estado de Bem-estar social que as políticas públicas se tornam mais abrangentes, alcançando um número maior de beneficiados. Entretanto, ao analisá-las de uma forma mais contextual, observando os questionamentos aqui mencionados, é perceptível o quanto essas ações não partiam da questão social em si, mas estavam subjugadas aos princípios ideológicos ligados à economia capitalista. Tratava-se, portanto, de diminuir as desigualdades resultantes do capitalismo, mas apenas com o objetivo de equilibrar a própria economia. A compreensão por meio da análise histórica é fundamental para a reflexão, ao apresentar uma sequência de ações que viabilizam um olhar mais global aos aspectos mais circunstanciais.

No caso brasileiro, resguardadas as especificidades, as políticas de cunho educacional seguiram as tendências de países que inseriram a ideologia neoliberal em suas reformulações, sob a justificativa da crise que, segundo os defensores neoliberais, advinha do Estado. A redefinição do papel do Estado, no contexto brasileiro, é um processo ainda em construção, entretanto as consequências negativas da inserção da lógica mercadológica, principalmente no cenário educacional, já é extremamente visível. Ao contrário do que fundamenta a ideia das políticas públicas, estas, sob a perspectiva neoliberal, não estão diminuindo as desigualdades resultantes do capitalismo. Ao oferecer uma educação que possui como princípio a lógica do mercado, desconsiderando os aspectos sociais tão necessários para agir com eficácia no cerne da questão, o Estado não só coaduna com as desigualdades econômicas e sociais, mas sentencia a sociedade a essa condição.

\section{Referências}

BRASIL. Plano Diretor da Reforma do Aparelho do Estado. Ministério da Administração Federal e Reforma do Estado, 1995.

CHESNAIS, François. A mundialização do capital. São Paulo, SP: Xamã, 1996.

DRAIBE, Sônia Miriam. O Welfare State no Brasil: Características e perspectivas. In: Ciências Sociais hoje. São Paulo, SP: ANPOCS/Vértice, p. 13-61, 1989. 
FARIAS, Adriana de Jesus Diniz. A crise do capital e a redefinição do papel do Estado como provedor de políticas educacionais. Belém, PA: Margens Interdisciplinares, vol. 8, n. 10, 2014.

HÖFLING, Eloisa de Mattos. Estado e políticas (públicas) sociais. Campinas, SP: Cadernos CEDES, v. 21, n. 55, p. 30-41, 2001.

MEDEIROS, Marcelo. A trajetória do Welfare State no Brasil: Papel redistributivo das políticas sociais dos anos 1930 aos anos 1990. Brasília, DF: Instituto de Pesquisa Econômica e Aplicada, 2001.

MORAES, Reginaldo. Neoliberalismo: De onde vem para onde vai? São Paulo, SP: Serviço Nacional de Aprendizagem Comercial, 2001.

SILVA, Leonardo Xavier da; SOUZA, Marcelino de. Estado e políticas públicas: Visões liberal, marxista e keynesiana do moderno Estado capitalista. Porto Alegre, RS: Editora da Universidade Federal do Rio Grande do Sul, 2010.

SOARES, Maria Clara Couto. Melhorar a qualidade da educação básica? As estratégias do Banco Mundial. In: DE TOMMASI, L.; WARDE, M. J.; HADDAD, S. (Orgs.). O Banco Mundial e as políticas educacionais. São Paulo, SP: Cortez, p. 125-194, 1998.

SOUZA, Celina. Políticas públicas: Uma revisão da literatura. Porto Alegre, RS: Sociologias, vol. 8, n. 16, 2006, p. 20-45.

PERONI, Vera Maria Vidal; OLIVEIRA, Regina Tereza Cestari de; FERNANDES, Maria Dilnéia Espíndola. Estado e Terceiro Setor: As novas regulações entre o público e o privado na gestão da educação básica brasileira. Campinas, SP: Educação \& Sociedade, vol. 30, n. 108, p. 761778, 2009.

TORRES, Rosa Maria. ONGs e o Banco Mundial: É Possível Colaborar Criticamente? In: DE TOMMASI, L.; WARDE, M. J.; HADDAD, S. (Orgs.). O Banco Mundial e as políticas educacionais. São Paulo, SP: Cortez, p. 41-74, 1998. 